\title{
AC 2007-1788: MEASURING CUSTOMER PERCEPTIONS: A FOLLOW-UP COLLABORATIVE PROJECT CONDUCTED BY STUDENTS FOR A MIDWEST TRUCKING COMPANY
}

Sorraya Khiewnavawongsa, Purdue University

Kathryne Newton, Purdue University

Edie Schmidt, Purdue University

Patrick Green, Purdue University 
Measuring Customer Perceptions: A Follow-Up Collaborative Project Conducted by Students for a Midwest Trucking Company 
Abstract

Companies are recognizing the benefits of working with universities on a variety of collaborative projects. The benefits, however, accrue to more than just the companies. The students, faculty, and companies all benefit from such partnerships, educationally and economically. ${ }^{1,5}$ The purpose of this paper is to share the results of a follow-up study with an industry partner, and to validate the benefit of collaboration between educational institute and industry. The first study was implemented in 2005 to identify customer perceptions related to key success factors for the trucking industry in general and the company in particular. The survey was conducted by Purdue University senior and graduate students, and was designed to collect customer responses rating a combination of qualitative and quantitative questions.

This study is the follow-up project of the previous study. ${ }^{6}$ For consistency, the methodology used to conduct the survey was similar to the previous study. Although some survey questions were adapted, the questions used to rate performance were kept the same as the first to allow for comparison of results. The survey was completed by telephone interview, fax, and email, and descriptive statistics were used for data analysis. This paper describes the process that was used to develop the survey and the methodology used to implement the survey. It also describes the advantages the company gained from the previous project in improving the operation and customer service.

The results of this study will be shown to verify that the company has improved their operation and customer service in efforts to improve customer satisfaction. The comparison of results of the two studies will be shown in graphic format. This paper will also delineate the benefits of the project; both the educational institute and industry partner have benefited from the collaboration.

Introduction

\section{Background}

In spring 2005, a Purdue University graduate course conducted a project for a trucking company in the Midwest. Recently, the management team at the company was more concerned about customer service. They realized that service was becoming more important in the trucking industry. Therefore, they initiated a project aiming at improving their customer services by conducting a survey from current customers. They preferred that the survey be conducted by a third party, which are likely to be impartial because they have no stake in the results. At the same time, a company had close contact with a faculty member at Purdue University. Faculty of the Industrial Technology Department at Purdue University brought students in several classes to the plant for a tour of operations. After that, the company contacted faculty in Purdue University seeking possible assistance with small project; this was how the collaboration started.

Simultaneously, Purdue University offered a graduate level course titled Global Supply Chain Management. Celadon's administrator had an agreement with a faculty member to let students in this class be responsible for this project. About the second week of the semester, one of a company's administrators visited a class and introduced a company. He explained what the 
company's expectations were for this project and provided information necessary for the project. Students developed key success factors and criteria for measurement. About a month later, a faculty member and several students visited the company. They spent half a day to discuss the project with the administrator, to interview staff members, and collect information regarding potential contacts and the development of a database. Then, students created the survey questions they believed were important to the project. At the same time, Celadon sent a list of contact information, including contact names, email addresses, and telephone numbers to the faculty. The contacts were randomly assigned to the graduate students, with each student receiving ten contact numbers. A clear script and survey instrument were provided for students, as well as a contact record to keep track of the surveys as they were made. Students were given ten days to conduct the survey. Two students were responsible for the statistical analysis. At the end of semester, students went with a Faculty member to the company and presented the report to the company's administrators. The company was very satisfied with the project. They realized what the problems were, and where to solve and improve to get higher level of customer satisfaction. Further verification of that they achieved what they wanted occurred when two further alliances were agreed to in order to follow up on the project. That led to the project described below.

\section{Project Objectives and purposes}

The purpose of this paper is to describe a follow-up project that was collaboratively conducted by a Purdue faculty member and a senior student with a moderate-sized Midwest trucking company. The results from this survey will be compared to the previous to identify improvements made since last year's collaboration. The purpose of the follow-up project was to develop and implement a survey to identify customer perceptions related to key success factors for the trucking industry in general and the company in particular. There were two primary tasks required for this project. The first was to rewrite the survey instrument and the second was to administer the survey. A survey and script was developed for the research. The administration included training the student to conduct the interviews, schedule appointments with respondents, administer the survey instrument, and collect the data. The second task was to survey approximately 50 customers that were provided for contact by Celadon.

\section{Project timeline}

The previous project concluded in summer of 2005 and the current project began in summer of 2006. Following is the current project timeline.

$\underline{\text { Timeline }}$

June

July

August

September - October
Solicit student help for project and enlist students in Human Subjects Training

Apply for Exemption from IRB

Company and IRB approval of Survey Instrument

Begin student training for survey administration

Administer surveys

Data analysis 
November - December

January-February

Methodology

Survey design
Prepare management report

Presentation and submit a report to Celadon Management

The survey was relatively short in length so that respondent inconvenience was minimized. Initial contact was made with respondents (provided by Celadon) by telephone, with the preference for immediate completion of the survey during the conversation. Respondents who were reluctant to complete the survey at that time were provided a faxed copy for completion and return by fax.

Survey Project Actions:

- Refine Survey Instrument

- Receive contact lists from Celadon and plan timeline for pilot test and student implementation of survey

- Pilot test of survey (2-3 people) and make adjustments as necessary, final approval

- Implementation of survey

- Validation of survey results and analysis of data (statistical results and development of graphs)

- Write management report detailing findings, conclusions and recommendations

\section{Survey questions}

The survey was originally created for a project conducted earlier. To provide for consistency in comparison of results, most questions remained the same as they were in the previous study. Some questions were added, deleted, and changed to get more useful information. However, the majority of questions were the same (see survey questions below). The survey was designed to collect customer responses to a combination of qualitative and quantitative questions. The data collected during the project was then compared to previous results to assess the operational improvements of the company.

The survey consisted of four major sections. The first section included the company demographic information, which were questions 1-3 of the survey. The purpose of this section was to identify the respondents' industry and general information. The second area was the customer service section, which included questions 4-10. The purpose of this section was to evaluate the relationship between respondents and Celadon, along with the performance of their services. The main results of this project were obtained from this section. The third section related to use of technology, and included questions 11-20. The primary objective of this section was to see if the respondents were using the Web tracking system provided by the company, and reasons why or why not. The last area was the general shipping information and included questions 21-23. The purpose of this section was to identify the respondents' shipping practices. Following is the list of questions used in the survey. 
Section 1: Company Demographic Information

1. What is your job title?

2. Is your company a manufacturer, wholesaler/distributor, retailer, $3^{\text {rd }}$ party logistics, or others?

3. What industry do you represent?

Section 2: Customer Service

4. List and rank the top three trucking companies you currently use for long-haul, dry-van trucking in order of preference? Indicate your use of each company as a percentage.*

5. What is most important to you in selecting a trucking company?*

6. List and rank the top three reasons you do business with Celadon.

7. What kind of trucking do you prefer using Celadon for?

8. Please rate Celadon performance the following services as well as rate the importance of each element.

9. Is Certification a requirement for your carrier?

10. Does Celadon meet your Certification Standards?

Section 3: Technology

11. Does your company use EDI (Electronic Data Interchange)?

12. Do you currently use Web tracking system? (If Yes, answer Question 13-17, if No, answer Question 18-20)

13. How often do you use Web tracking system?

14. Is Web tracking system easy to use?

15. Have you ever had any training on how to use Web tracking system?**

16. Would you like to have formal training by Celadon on how to use Web tracking system?**

17. What features would you like to see added to Web tracking system?

18. Why don't you use Web tracking system?**

19. Have you ever had any training on how to use Web tracking system?**

20. Would you like to have formal training by Celadon on how to use Web tracking system?**

Section 4: General Shipping Information

21. What percentage of your shipping is done in North American (including Canada and Mexico)?

22. How much money do you spend on shipping (in US dollars)?**

23. Please describe any other major trends, issues or changes in your shipping practices that you see affecting your company?

Note $*$ indicates question was edited from the previous survey

** indicates question was added from the previous survey

\section{Survey Administration}

An undergraduate student was hired to conduct the survey in August 2006. The duration of data collection was estimated to be two to four weeks. To begin the project, he was provided with a 
script, the survey, a list of customer contacts, and a form to use to keep track of their calls. The company provided 150 contact telephone numbers, along with email address. A Purdue University long-distance access code was also provided with instructions for use.

An email was sent to the contact lists approximately two weeks ahead of time to notify them about the survey. After two weeks, a student made the next contact by telephone. He called all of the numbers on the contact lists. Several respondents replied by telephone. There were a few fax replies, but typically those who asked for a fax copy did not respond. The time to complete the surveys was extended due to the difficulty of getting responses. Out of 150 , fifteen were completed resulting in a ten percent response rate.

Some difficulties were found by the student in conducting the surveys. Difficulties included:

- No answers to telephone calls

- Direct refusals due to lack of time to complete surveys

- Requests for call backs and/or fax copies of the survey

- Spanish-speaking respondents

- One-time/new customers that did not have enough experience to respond to the questions

\section{Data Analysis}

In this project, the data analysis was conducted by a graduate student. She was one of two students who did data analysis for the previous project and was therefore familiar with the project. Microsoft Excel was used for data analysis because it was easy to use for comparison with the first group of date, and it provided sufficient presentation capability. The outcomes of data analysis are detailed in both numerical and graphical formats.

Results

Similar to the previous study, the findings for the company included the respondent ratings for basic services provided by the company, as well as detailed feedback related to the companies web-based tracking system. The service characteristics were rated on a scale of one to five with five representing the excellent performance and one representing very poor performance. If respondents were not familiar with the service, they could answer "don't know," which did not count in calculations. Table 1 shows the average scores for performance in basic services provided by Celadon in year 2005 and 2006, along with the percentages improvement. The numbers in brackets are the rank of the item for each year. This table is sorted in descending order by the percentage improved from the previous year.

\begin{tabular}{|l|c|c|c|}
\hline \multicolumn{1}{|c|}{ Services } & $\mathbf{2 0 0 6}$ & $\mathbf{2 0 0 5}$ & $\begin{array}{c}\text { Improvement } \\
\text { Percentage }\end{array}$ \\
\hline Adequate Communication from Pickup to Delivery & $4.20(11)$ & $3.55(12)$ & $18.31 \%$ \\
\hline Billing Accuracy & $4.47(2)$ & $3.81(10)$ & $17.24 \%$ \\
\hline On-time delivery & $4.47(2)$ & $3.86(9)$ & $15.72 \%$ \\
\hline Capacity requirements & $4.00(12)$ & $3.52(13)$ & $13.64 \%$ \\
\hline Driver courtesy & $4.33(7)$ & $3.89(7)$ & $11.40 \%$ \\
\hline
\end{tabular}




\begin{tabular}{|l|c|c|c|}
\hline Timely response to requests & $4.30(9)$ & $3.90(6)$ & $10.26 \%$ \\
\hline Timely rate quotations & $4.27(10)$ & $3.88(8)$ & $9.97 \%$ \\
\hline On-time pickup & $4.37(6)$ & $4.07(5)$ & $7.29 \%$ \\
\hline Availability of customer support & $4.00(12)$ & $3.75(11)$ & $6.67 \%$ \\
\hline Product tracking & $4.33(7)$ & $4.20(4)$ & $3.17 \%$ \\
\hline Condition of Equipment & $4.47(2)$ & $4.35(3)$ & $2.68 \%$ \\
\hline Product security & $4.60(1)$ & $4.48(1)$ & $2.68 \%$ \\
\hline EDI transactions & $4.47(2)$ & $4.38(2)$ & $1.98 \%$ \\
\hline
\end{tabular}

Table 1. Comparison of Celadon Service Ratings between 2006 and 2005

For the current study (refer to column 2006 in Table 1), the services that customers were most satisfied with included product security, EDI transactions, condition of equipment, billing accuracy, and on-time delivery. Services that customers were least satisfied with the company were capacity requirements, the availability of customer support, and the communication from pickup to delivery.

In the previous study (column 2005), the services that customers were most satisfied with included product security, EDI transactions, and condition of equipment. Services that customers were least satisfied with the company were capacity requirements, the communication from pickup to delivery, and the availability of customer support.

When making a comparison of the two studies, it can be noticed that the most and least satisfied services remained the same. Three services that customer were most satisfied with in 2005 were still ranked top in 2006, with a slight improvement, 1.98-2.68 percent. It may imply that the two groups of respondents had consistent viewpoints and provides some validity to the data. On the other hand, the three services that customers were least satisfied with were still bottom rank in 2006. However, the average score was increased significantly. The capacity requirements service characteristic improved from 3.52 in 2005 to 4.00 in 2006, which is $13.64 \%$. The adequate communication from pickup to delivery service characteristic improved from 3.55 in 2005 to 4.20 in 2006 , which is $18.31 \%$. The availability of customer support service characteristic improved from 3.75 in 2005 to 4.00 in 2006, which is a $6.67 \%$ improvement.

Another important point is that all thirteen services averaged a score of at least 4.00 out of 5 , compared to five services in 2005. The average scores of all service were 3.97 in 2005 and 4.33 in 2006 , increasing $8.96 \%$ in a year.

The survey also asked respondents to rate each service's level of importance on a scale of one to five with five representing the utmost importance and one representing the least importance. Table 2 shows the average scores of service importance, along with performance scores, and their ranks.

\begin{tabular}{|l|c|c|c|c|}
\hline \multicolumn{1}{|c|}{ Services } & Performance & Rank (P) & Importance & Rank (I) \\
\hline On-time delivery & 4.47 & 2 & 4.79 & 1 \\
On-time pickup & 4.37 & 6 & 4.71 & 2 \\
Timely response to requests & 4.30 & 9 & 4.60 & 3 \\
Billing Accuracy & 4.47 & 2 & 4.57 & 4
\end{tabular}


Capacity requirements

Product security

Availability of customer support

Condition of Equipment

Adequate Communication from Pickup to Delivery

EDI transactions

Product tracking

Timely rate quotations

Driver courtesy

\begin{tabular}{l|c}
4.00 & 12 \\
4.60 & 1 \\
4.00 & 12 \\
4.47 & 2 \\
4.20 & 11 \\
4.47 & 2 \\
4.33 & 7 \\
4.27 & 10 \\
4.33 & 7
\end{tabular}

\begin{tabular}{l|c|c|}
2 & 4.50 & 5 \\
1 & 4.43 & 6 \\
2 & 4.40 & 7 \\
2 & 4.36 & 9 \\
1 & 4.36 & 8 \\
2 & 4.14 & 11 \\
7 & 4.14 & 10 \\
0 & 4.00 & 12 \\
7 & 3.93 & 13 \\
\hline
\end{tabular}

Table 2. Performance and Importance Ratings

Originally, the question about the importance of services was not included in the previous study. This question was one of the suggestions that arose after the previous project had ended. It was added to the latest survey to see what services are important for the customers. From Table 2, customers focus on the on-time delivery, on-time pickup, and timely response to requests the most. They all were related to "time." The most important service, on-time delivery has the average score of 4.47, which is the second highest in rank. However, the next two most important services, on-time pickup and timely response o requests have only 4.37 and 4.30 , which ranked $6^{\text {th }}$ and $9^{\text {th }}$ respectively. Therefore, Celadon should pay attention to these services.

In addition to the questions about service satisfaction, this survey also included questions asking respondents about Celadon and its industry. Table 3 shows the most important factor for respondents in selecting a trucking company. This question was originally designed to have only one answer. However, most respondents provided more than one.

\begin{tabular}{|l|c|c|}
\hline & Total Number & Percentage \\
\hline Service & 6 & $40 \%$ \\
\hline Price/Cost & 5 & $33 \%$ \\
\hline On-time & 4 & $27 \%$ \\
\hline Reliability & 4 & $27 \%$ \\
\hline Availability & 1 & $7 \%$ \\
\hline Network Fit & 1 & $7 \%$ \\
\hline Capacity & 1 & $7 \%$ \\
\hline Business relations & 1 & $7 \%$ \\
\hline Ease of operate with & 1 & $7 \%$ \\
\hline Certification & 1 & $7 \%$ \\
\hline
\end{tabular}

Table 3. Important Factors in Selecting Trucking Company

The top three factors from last year's results were price/cost (35\%), service (31\%), and availability (13\%). They have changed in this year's results to service, price/cost, on-time delivery, and reliability. It can be noticed that price/cost and service were always the most important factor for customers in choosing a trucking company.

Another important question that Celadon wanted to know was the primary reason that customers choose them as a freight provider. Respondents could answer up to three reasons. The results are shown in the Table 4. 


\begin{tabular}{|l|c|c|}
\hline & Total Number & Percentage \\
\hline Price & 7 & $47 \%$ \\
\hline On-times & 5 & $33 \%$ \\
\hline Customer service & 3 & $20 \%$ \\
\hline Reliability & 3 & $20 \%$ \\
\hline Ability to do business with & 3 & $20 \%$ \\
\hline Performance & 3 & $20 \%$ \\
\hline Dependability & 2 & $13 \%$ \\
\hline Mexico/International delivery & 2 & $13 \%$ \\
\hline Capacity & 2 & $13 \%$ \\
\hline Relationship & 2 & $13 \%$ \\
\hline Acquire the company & 2 & $13 \%$ \\
\hline Sales representative & 1 & $7 \%$ \\
\hline Availability & 1 & $7 \%$ \\
\hline Loyalty & 1 & $7 \%$ \\
\hline
\end{tabular}

Table 4. Reasons That Customers Choose Celadon

Almost half of the respondents chose Celadon because of its competitive price. About one-third said it's because they had on-time delivery/pickup.

Celadon was also interested in customer's perspective to their Web tracking system technology. The followings were important conclusions about the Web tracking system.

- Three respondents (20\% of total respondent) were not aware of Web tracking system.

- Most respondents (12 out of 13) did not want formal training on the Web tracking system.

- Only one respondent had ever had Web tracking system training from Celadon before.

- All respondents who stated they never used the Web tracking system also had never heard about available training for the Web tracking system.

- International trucking and coast-to-coast trucking were two trucking types that respondents most preferred Celadon for over other competitors; each counted for $40 \%$. Only $20 \%$ use Celadon when they need interstate trucking

- Three respondents (50\% of respondents who use Web tracking system) use it daily, while one uses it weekly. Two respondents use it only when they need to.

\section{Management Report}

Faculty and students plan to visit the company between mid January and February. The purpose of this visit will be to make a presentation of the findings and comparisons, as well as further recommendations for future service improvements. In addition, conclusions will be made regarding the two completed projects. Some examples of the recommendations for the company are listed below. 
- There is room for improvement for on-time pickup and timely response to requests. These are the second and third most important factors for customers with rankings of $6^{\text {th }}$ and $9^{\text {th }}$ for performance.

- Celadon should place high priority on keeping prices competitive. Thirty three percent said price is the most important factor in selecting a trucking company and $47 \%$ of current customers choose Celadon because of the price.

- Consider researching customer segments in the areas of textile, aerospace, food and chemical industries to identify new business opportunities.

- Conduct future research to find out how major competitors operate and what services provided by these trucking companies may be different.

- Continue to provide more efficient services at competitive prices and to make strengths highly visible to customers.

- Work to increase capacity and advertise to potential customers.

- Benchmark against "best practices" in industry.

- Continue to educate the company customers in how the company goes about ensuring adherence to certification standards.

- Conduct a survey to find out what features of the web tracking system are most popular or highly valued by customers and make visible to all customers.

- Continue to maintain the user-friendliness of the web tracking system, train personnel to ask about usage of system.

- Develop a program to assist customers needing to register to use web tracking system and "walk" them through first-time use.

- Continue to enhance promotion of web tracking system to non-users.

\section{Discussions}

From the results, it can be concluded that an initial collaboration project between Department of Industrial Technology at Purdue University and Celadon Trucking Company was successful. This project is not the first collaboration between academia and industry. There have been several projects and research studies in various disciplines conducted at universities nationwide. Some examples include an engineering senior project at Pennsylvania State University at New Kensington that was conducted with the collaboration of local industry, ${ }^{4}$ and the Engineering Technology Department at Middle Tennessee State University teaming with the local industrial community became well adapted to research and development projects for the students. ${ }^{2}$ Resulting collaborations are advanced in many ways, including long-term partnerships, informal contacts between faculty members and industrial personnel, and consulting, as well as opportunities to work together on training, discussions, seminars, and teaching programs. Furthermore, students benefited from the related assignments.

These two studies were only a few examples. Successful outcomes are normally the results of collaborations between academic and industry. It confirms the survey results in this study. The collaboration increases the university/industry appreciation and awareness, which leads to better relations and mutual trust. ${ }^{3}$ For the companies involved, it may increase revenues, enhance reputation, and increase business development opportunities. For university faculty, the collaboration provides much-needed exposure to practical applications and industry trends that 
can be communicated in the classroom, and enhances faculty development and equipment procurement opportunities.

\section{Conclusions}

The project was beneficial to both the company and the university faculty and students who were involved. The company will be presented the findings early in spring of 2007. This partnership has been highly successful with Celadon, as this is only one of the follow-up studies that was undertaken as a result of the first study. Additionally, one M.S. student recently graduating after conducting a work-flow project with the company that became his M.S. thesis, and another class project is being explored. Faculties were provided with opportunities for conference papers and presentations, and the company continues this collaboration as a result of such positive experiences.

\section{References}

1. Exploring common ground: A report on business/academic partnership. Washington, D.C. American Association of State Colleges and Universities. (1987).

2. Foroudastan and Hardymon (2003). Innovative applied research projects using industry collaboration. Innovations and Applied Research in Mechanical Engineering Technology, 3, 7-10.

3. Mead N., Beckham K., Lawrence J., O’Mary G., Parish C., Unpingco P., et al. (1999). Industry/University Collaborations: Different Perspectives Heighten Mutual Opportunities. Journal of Systems and Software, 49, 155162.

4. Mueller, R. L. A Senior Project Done in Collaboration with Industry. Proceedings of the American Society for Engineering Education, Montreal, Canada (2002)

5. Newton, K.A. \& Schmidt, E.K. A successful partnership between an industrial trade association and education at Purdue University. 2003 Conference for Industrial and Education Collaboration Proceedings. Tucson, AZ. (January, 2003).

6. Newton, K. A., Khiewnavawongsa, S., Schmidt, E. K., and Nashine, R. Measuring customer perceptions: A collaborative project conducted by students for a Midwest trucking company. Proceedings of the American Society for Engineering Education, Chicago, IL. (2006). 